\title{
Genetic variation of myeloperoxidase gene contributes to aggressive periodontitis: A preliminary association study in Turkish population
}

\author{
Kamile Erciyas ${ }^{\mathrm{a}, *}$, Sacide Pehlivan ${ }^{\mathrm{b}}$, Tugce Sever ${ }^{\mathrm{b}}$ and Recep Orbak ${ }^{\mathrm{c}}$ \\ ${ }^{a}$ Department of Periodontology, Gaziantep University Faculty of Dentistry, 27310 Gaziantep, Turkey \\ ${ }^{\mathrm{b}}$ Department of Medical Biology and Genetics, Gaziantep University Faculty of Medicine, 27310 Gaziantep, Turkey \\ ${ }^{\mathrm{c}}$ Department of Periodontology, Ataturk University Faculty of Dentistry, 25240 Erzurum, Turkey
}

\begin{abstract}
Myeloperoxidase (MPO) is a lysosomal enzyme found in the azurophilic granules of polymorphonuclear leukocytes. It is involved in the defense against periodontal bacteria, and is also able to mediate inflammatory tissue destruction in aggressive and chronic periodontitis. The aim of this study was to explore the association between MPO-463G/A gene polymorphism and aggressive periodontitis (AgP) and chronic periodontitis (CP). The study included 147 subjects. Probing depth (PD), clinical attachment loss (CAL), plaque index (PI), and gingival index (GI) were recorded as the clinical parameters. Genomic DNA was obtained from the peripheral blood of 32 subjects with $\mathrm{AgP}, 25$ with $\mathrm{CP}$, and 90 reference controls. We genotyped the MPO-463G/A polymorphism using the PCR-RFLP method. All data were analyzed using SPSS version 13.0 for windows. There were no significant differences between the CP patients and controls regarding MPO-463A/G gene polymorphism either in terms of allele frequency or genotype frequency of MPO-463A/G. However, either in terms of allele frequency or genotype frequency of MPO-463A/G, there were significant differences between the AgP patients and the controls. In conclusion, our data suggest that MPO-463G/A may be associated with increased risk of aggressive periodontitis in Turkish patients.
\end{abstract}

Keywords: Periodontal disease, myeloperoxidase, gene polymorphism, DNA, PCR-RFLP

\section{Introduction}

Periodontitis is the most prevalent chronic destructive inflammatory disease affecting teeth and their supporting tissue including bone in humans [1]. The progression of periodontal diseases, initially originating from bacterial colonization, from gingivitis to advanced forms of periodontitis is modified by several factors including immunological, environmental, and genetic, as well as age, sex, and race [2-4]. Gene expres-

*Corresponding author: Kamile Erciyas, Gaziantep University Faculty of Dentistry, Department of Periodontology, Gaziantep, TR27310, Turkey. Tel.: +903423606060 (76611); Fax: +90 342361 03 46; E-mail: kmlercys@ @otmail.com, erciyas@gantep.edu.tr. sion profiling of local and peripheral cells may identify genes expressed in subjects with periodontal disease [5]. Blood neutrophils of subjects with periodontitis produce high levels of proteolytic enzymes and reactive oxygen species, and microarray analyses showed molecular defects in signal transduction [6,7].

Myeloperoxidase (MPO) is an enzyme that catalyzes the formation of microbicidial hypochlorous acid enabling defense against the bacteria involved in the pathogenesis of various inflammatory diseases including periodontitis [8]. During inflammation, myeloperoxidase and eosinophil peroxidase are generated by phagocytic white blood cells, such as neutrophils and eosinophils [9]. It is generally thought that MPO kills microorganisms by oxidizing chloride $\left(\mathrm{Cl}^{-}\right)$in- 


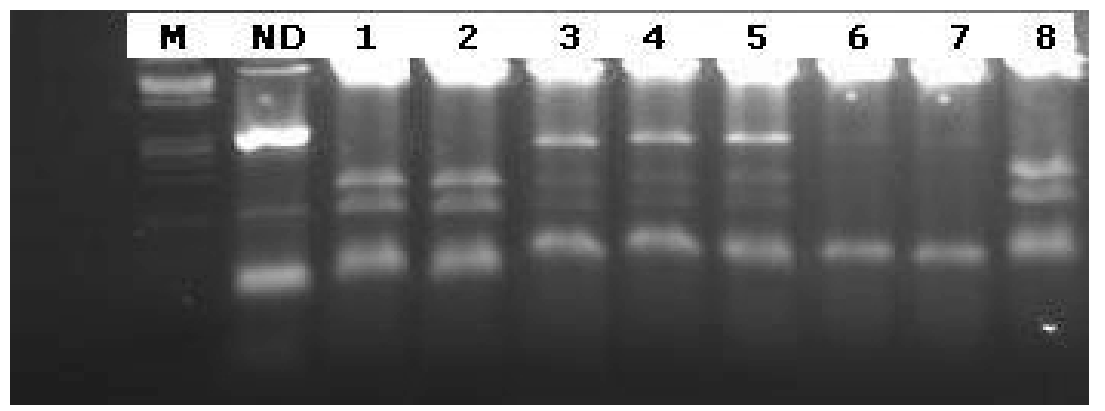

Fig. 1. Agarose gel electrophoresis of MPO DNA fragments stained with ethidium bromide (M: DNA size standard, ND: Non-digest PCR product.) It is shown for AgP patients; 1,2,8:GG, 3,5:GA, 6,7:AA.

to hypochlorous acid, a highly reactive and toxic oxidant, which is able to oxidize many biomolecules substantially faster than it does $\mathrm{H}_{2} \mathrm{O}_{2}[10,11]$. The initial product of the MPO- $\mathrm{H}_{2} \mathrm{O}_{2}-\mathrm{Cl}$ system is the potent antimicrobial oxidant hypochlorous acid/hypochlorite ( $\mathrm{HOCl} / \mathrm{OCl})$. However, under pathological conditions, persistent activation of the MPO- $\mathrm{H}_{2} \mathrm{O}_{2}$ system of activated phagocytes may adversely affect tissues [12].

The $M P O$ gene is highly polymorphic and one of the most common single nucleotide polymorphisms in the promoter region of the gene, $-463 \mathrm{G} / \mathrm{A}$, was found to be functionally important $[13,14]$. This polymorphism was reported to be associated with coronary artery disease [15], helicobacter pylori infections [16], neurodegenerative disorders [17,18], lung cancer [19], and periodontal disease [20]. No data have been published to date on $M P O-463$ G/A gene polymorphism in different periodontal diseases. Pursuing this interest, we investigated whether the $-463 \mathrm{G} / \mathrm{A}$ polymorphism of the $M P O$ gene was associated with the risk of aggressive and chronic periodontitis in the Turkish population.

\section{Subjects and methods}

This study was performed at the Department of Periodontology in the Dental Faculty at Gaziantep University. The study protocol was approved by the Ethical Committee of Gaziantep University Medical Faculty, Turkey. The patients were informed about the purpose and method of the study, and they all agreed to participate. All of the subjects were chosen from those patients without any systemic or oral disease except for peridontitis, and from those who were non-smokers. The exclusion criteria were pregnancy, lactation period, and intake of antibiotics or anti-inflammatory drugs in the previous 6 months, and systemic diseases with an influence on periodontitis. A detailed medical, oral, and family medical history was taken, followed by a complete periodontal examination and appropriate radiographs. For periodontitis patients, measurements of probing depth (PD) and clinical attachment loss (CAL) were made at six sites (mesiobuccal, buccal, distobuccal, mesiolingual/palatal, palatal/lingual, distolingual/palatal) for each tooth using a manual periodontal probe (Williams' periodontal probe designed with $1,2,3,5,7,9$, and $10 \mathrm{~mm}$ calibrations). Gingival index (GI) [21] and plaque index (PI) [22] were recorded at four sites (mesiobuccal, buccal, distobuccal, and palatal/lingual). The patients were diagnosed according to the criteria of the IWC 1999 International Workshop for a Classification of Periodontal Diseases and Conditions, and were assigned to have AgP and CP [1]. The patients and controls were from the same geographical areas.

Peripheral blood samples were collected in tubes containing EDTA (ethylenediamine tetraacetate) from both the healthy control group and patients with AgP and $\mathrm{CP}$ and stored at $-20^{\circ} \mathrm{C}$ until analysis. DNAs were isolated using the salt precipitation method [23].

The region with a -463 polymorphism located at the promoter of the MPO gene was multiplified by PCR using MPOF (5' CGGTATAGGCACAATGGTGAG) and MPOR (5', GCAATGGTTCAAGCGATTCTTC) primary chains and an amplification control was performed with $2 \%$ agarose gel electrophoresis. The a amplified region was incubated for 16 hours with 5 units of Aci I enzyme at $37^{\circ} \mathrm{C}$ and analyzed with $3 \%$ agarose gel electrophoresis [24] (Fig. 1).

\section{Statistical analyses}

Analyses of data were performed using the computer software SPSS for Windows (version 13.0; SPSS Inc., 
Table 1

Demographic and clinical data of patients with periodontal disease and healthy controls

\begin{tabular}{lccc}
\hline Variable & Controls $(\mathrm{N}=90)$ & $\operatorname{AgP}(\mathrm{N}=32)$ & $\mathrm{CP}(\mathrm{N}=25)$ \\
\hline Sex (Female/Male) & $56 / 34$ & $19 / 13$ & $13 / 12$ \\
Parental consanguinity & 15 & 14 & 5 \\
PD (mm) & $1.9 \pm 0.4$ & $5.6 \pm 1.7$ & $4.7 \pm 1.4$ \\
CAL (mm) & $2.1 \pm 0.2$ & $5.8 \pm 1.42$ & $5.4 \pm 1.5$ \\
PI & $0.6 \pm 0.09$ & $1.8 \pm 0.32$ & $1.9 \pm 0.26$ \\
GI & $0.4 \pm 0.1$ & $2.01 \pm 0.39$ & $2 \pm 0.27$ \\
\hline
\end{tabular}

AgP: Aggressive periodontitis, CP: Chronic periodontitis, PD: probing depth, CAL: clinical attachment loss, PI: plaque index, GI: gingival index.

Table 2

Genotype distribution and allele frequencies of MPO gene -463G/A polymorphism in patients with periodontal disease and healthy controls

\begin{tabular}{|c|c|c|c|c|}
\hline MPO (-463G/A) & Control N (\%) & ${ }^{\mathrm{a}} \mathrm{AgP} \mathrm{N}(\%)$ & ${ }^{\mathrm{b}} \mathrm{CP} N(\%)$ & $\mathrm{p}\left(\mathrm{X}^{2}\right)$ \\
\hline \multicolumn{5}{|l|}{ Genotype } \\
\hline GG & $62(63.8)$ & $11(34.4)$ & $14(56)$ & $\begin{array}{l}0.009^{\mathrm{a}} \\
0.438^{\mathrm{b}}\end{array}$ \\
\hline $\mathrm{AG}$ & $24(26.6)$ & $14(43.8)$ & $8(32)$ & $\begin{array}{l}0.000^{\mathrm{a}} \\
0.125^{\mathrm{b}}\end{array}$ \\
\hline AA & $4(4.4)$ & 7 (21.9) & $3(12)$ & $\begin{array}{l}0.000^{\mathrm{a}} \\
0.228^{\mathrm{b}}\end{array}$ \\
\hline $\begin{array}{l}\text { Total } \\
\text { Allele }\end{array}$ & 90 & 32 & 25 & \\
\hline A & $32(17.7)$ & $28(43.8)$ & $14(28)$ & $0.000^{\mathrm{a}}$ \\
\hline G & $148(82.3)$ & $36(56.2)$ & $36(72)$ & $0.000^{\mathrm{b}}$ \\
\hline Total & 180 & 64 & 50 & \\
\hline HWE & 0.404 & 0.529 & 0.302 & \\
\hline
\end{tabular}

Chicago, IL). The data were analyzed for appropriateness between the observed and expected genotypes as well as for Hardy-Weinberg Equilibrium (HWE) [25]. All analyses and differences were interpreted as statistically significant when $p<0.05$.

\section{Results}

The study group included 32 subjects with $\mathrm{AgP}$ $(31.7 \pm 9.9$ years of age $), 25$ subjects with $\mathrm{CP}(46.9 \pm$ 9.9 years of age), and 90 healthy volunteers $(42.8 \pm$ 10.7 years of age). Demographic and clinical data of patients with $\mathrm{AgP}$ and $\mathrm{CP}$ and control groups are shown in Table 1.

There was no significant difference between the $\mathrm{CP}$ patients and controls regarding MPO-463A/G gene polymorphism either in terms of allele frequency or genotype frequency of MPO-463A/G. However, either in terms of allele frequency or genotype frequency of MPO-463A/G, there were significant differences between the AgP patients and the controls (Table 2). The frequencies of $\mathrm{AG}$ and $\mathrm{AA}$ genotypes in the MPO-
463A/G gene polymorphism were more common in the $\mathrm{AgP}$ patients when compared to the controls $\left(p_{A G}=\right.$ $\left.0.000, p_{A A}=0.000\right)$.

No significant associations were detected in terms of HWE in the analysis of MPO-463A/G polymorphism in either the $\mathrm{AgP}$ and the $\mathrm{CP}$ groups or control group (Table 2).

\section{Discussion}

To our knowledge, this is the first study to link the MPO-463G/A polymorphism with AgP and CP and it shows that this polymorphism is associated with an increased risk of $\mathrm{AgP}$ in the Turkish population (Fig. 1, Table 2).

The involvement of MPO in inflammatory diseases has been supported by genetic studies reporting an association with the $-463 \mathrm{G} / \mathrm{A}$ polymorphism located in the promoter region of the MPO gene [14-19]. It is well known that MPO activity is increased in inflammatory gingival tissue and gingival crevicular fluid [26, 27]. The polymorphism of the MPO gene promoter af- 
fects the risk of periodontal diseases. Recently, Meisel et al. [19] have reported an association between MPO463G/A polymorphism and periodontal disease. They examined more than 3000 subjects, including 1083 patients (the rest were controls) and found that females with GG genotype were $50 \%$ more susceptible to periodontal disease, apparently because MPO released by reactive neutrophils damages the cells. According to the study, it was stated that through MPO G/A base change, mRNA expression and MPO level were decreased; however, MPO production was increased by the $\mathrm{G}$ allele in subjects with MPO $-463 \mathrm{G} / \mathrm{A}$ polymorphism [28]. Atzeni et al. [29] did not find any association between the -463 G/A MPO promoter polymorphism and susceptibility to, and clinical expression of, Behcet's disease. In the study, it was stated that the A allele in MPO-463G/A polymorphism might be related to atherosclerosis risk factors. In a different study, an association between increased risk of coronary artery disease and the GG genotype of MPO -463G/A polymorphism has been reported [14]. Asselbergs et al. [30] stated that the MPO-463G/A and AA genotypes decreased MPO expression twofold when compared with GG genotype. In the literature, the MPO-463G/A polymorphism has been associated with to Alzheimer's disease (AD) [16] and multiple sclerosis [17] where the GG genotype has been associated with a higher incidence of disease in women. More recently, Reynolds et al. [31] have shown that the A allele was associated with an increased risk for AD in men carrying the MPO. These studies provide strong evidence that the polymorphism does result in a difference in MPO activity that affects disease susceptibility. Therefore, MPO protects against microbial invasion, whereas in inflammatory disease states, it unintentionally contributes to cell damage [32]. However, the assessment of MPO as a biological marker requires knowledge of its biological variations, which are poorly documented.

The precise mechanisms underlying the relationship of the MPO polymorphism and periodontal disease remain unclear. MPO protein is mainly expressed at high levels in neutrophils, monocytes and some reactive microglial [31]. The $\mathrm{G}$ allele is the wild type with normal MPO expression, while the A allele is a lowexpression allele [12]. There were no significant differences between the CP patients and controls regarding MPO-463A/G gene polymorphism either in terms of allele frequency or genotype frequency of MPO-463A/G. However, either in terms of allele frequency or genotype frequency of MPO-463A/G, there were significant differences between the AgP patients and the controls
(Table 2). Importantly, we found that the MPO-463 AA genotype or A allele had a role in susceptibility to AgP and that the presence of the A allele had a 10 times greater risk for $\mathrm{AgP}$ (Odds-ratio=3.159-0.315, $p=0.000$ ) (Table 2). Moreover, the GG genotype at the MPO-463G/A gene was more prevalent in controls than in AgP patients, suggesting that the GG genotype may serve as a protective factor against AgP.

Our subjects with AgP and CP and the healthy controls did not satisfy the HWE. This might be explained by the fact that both cohorts represent highly selected groups, which could be genetically different from the average population [33].

Within the limitations of this study, it is reported that MPO-463 gene polymorphism demonstrated a significant association with AgP. The different association of $\mathrm{AgP}$ and $\mathrm{CP}$ with this gene polymorphism may help to explain the differing aetiopathogenesis of $\mathrm{AgP}$ and CP. However, this data could explain only a small proportion of genetic susceptibility to periodontal disease. Furthermore, the possible role of MPO gene polymorphisms in periodontal diseases, including several factors such as genetic variation, age, sex, smoking and environmental and immunological factors, may therefore be worthy of further investigation. Further investigations addressing this question may yield clues to a more complete understanding of the role of the MPO gene in periodontal disease. In addition, further study may provide access to new drug targets and facilitate both pharmacological therapy and prevention of periodontal disease in the future.

In conclusion, our data suggest that MPO-463G/A may be associated with increased risk of aggressive periodontitis in Turkish patients.

\section{References}

[1] G.C. Armitage, Development of a classification system for periodontal diseases and conditions, Ann Periodontol 4 (1999), $1-6$.

[2] J.M. Albandar, Global risk factors and risk indicators for periodontal diseases, Periodontol 200029 (2002), 177-206.

[3] M.E. Nunn, Understanding the etiology of periodontitis: an overview of periodontal risk factors, Periodontol 200026 (2003), 113-134.

[4] B.S. Michalowicz, S.R. Diehl, J.C. Gunsolley, B.S. Sparks, C.N. Brooks, T.E. Koertge, J.V. Califano, J.A. Burmeister and H.A Schenkein, Evidence of a substantial genetic basis for risk of adult periodontitis, J Periodontol 71 (2000), 1699-1707.

[5] N.U. Zitzmann, J. Lindhe and T. Berglundh, Host response to microbial challenge following respective/non respective periodontal therapy, J Clin Periodontol 32 (2005), 1175-1180. 
[6] K. Gronert, A. Kantarci, B.D. Levy, C.B. Clish, S. Odparlik, H. Hasturk, J.A. Badwey, S.P. Colgan, T.E. Van Dyke and C.E. Serhan, A molecular defect in intracellular lipid signaling in human neutrophils in localized aggressive periodontal tissue damage, J Immunol 172 (2004), 1856-1861.

[7] J.A. Lekstrom-Himes and J.I. Gallin, Immunodeficiency diseases caused by defects in phagocytes, $N$ Engl J Med 343 (2000), 1703-1714.

[8] K.T. Miyasaki and E. Nemirovskiy, Myeloperoxidase isoform activities released by human neutrophils in response to dental and periodontal bacteria, Oral Microbiol Immunol 12 (1997), 27-32.

[9] A. Chapman, O. Skaff, R. Senthilmohan, A.J. Kettle and M. Davies, Hypobromous acid and bromamine production by neutrophils and modulation by superoxide, Biochem J 417 (2009), 773-781.

[10] S.J. Klebanoff, Myeloperoxidase: friend and foe, J Leukoc Biol 77 (2005), 598-625.

[11] B. Halliwell and J.M.C. Gutteridge, Free Radicals in Biology and Medicine, Oxford University Press Inc., New York, 2007.

[12] D.C. Dale, L. Boxer and W.C. Liles, The phagocytes: neutrophils and monocytes, Blood 112 (2008), 935-945.

[13] F.J. Piedrafita, R.B. Molander, G. Vansant, E.A. Orlova, M. Pfahl and W.F. Reynolds, An Alu element in the myeloperoxidase promoter contains a composite SP1-thyroid hormoneretinoic acid response element, J Biol Chem 271 (1996), $14412-14420$.

[14] C.B. Ambrosone, J. Ahn, K.K. Singh, H. Rezaishiraz, H. Furberg, C. Sweeney, B. Coles and A. Trovato, Polymorphisms in genes related to oxidative stress (MPO, MnSOD, CAT) and survival after treatment for breast cancer, Cancer Res 65 (2005), 1105-1111.

[15] B. Nikpoor, G. Turecki, C. Foumiere, P. Theroux and G.A Rouleau, Myeloperoxidase polymorphic variant is associated with coronary artery disease in French-Canadians, Am Heart $J 142$ (2001), 336-339.

[16] N. Hamajima, K. Matsuo, T. Suzuki, T. Nakamura, T. Matsuura, K. Tayima and S. Tominaga, Low expression myeloperoxidase genotype negatively associated with Helicobacter pylori infections, Jpn J Cancer Res 92 (2001), 488-493.

[17] W.F. Reynolds, J. Rhees, D. Maciejewski, T. Paladino, R.A. Maki and E. Masliah, Myeloperoxidase polymorphism is associated with gender specific risk for Alzheimer's disease, Exp Neurol 155 (1999), 31-41.

[18] R.M. Nagra, B. Becher, W.W. Tourtellotte, J.P. Antel, D. Gold, T. Paladino, R.A. Smith, J.R. Nelson and W.F. Reynolds, Immunohistochemical and genetic evidence of myeloperoxidase involvement in multiple sclerosis, J Neuroimmunol 78 (1997), 97-107.

[19] S.J. London, T.A. Lehman and J.A. Taylor, Myeloperoxidase genetic polymorphism and lung cancer risk, Cancer Res $\mathbf{5 7}$ (1997), 5001-5003.

[20] P. Meisel, T. Krause, I. Cascorbi, W. Schoeder, F. Herrmann, U. John and T.H. Kocher, Gender- and smoking-related risk reduction of periodontal disease with variant myeloperoxidase alleles, Gene Immunol 3 (2002), 102-106.

[21] H. Löe and J. Silness, Periodontal disease in pregnancy I.
Prevalence and severity, Acta Odont Scand 21 (1963), 533551.

[22] J. Silness and H. Löe, Periodontal disease in pregnancy II. Correlation between oral hygiene and periodontal condition, Acta Odontol Scand 24 (1964), 121-135.

[23] S.A. Miller, D.D. Dykes and H.F. Polesky, A simple salting out procedure for extracting DNA from human nucleated cells, Nucleic Acids Res 16 (1988), 1215.

[24] I. Cascorbi, S. Henning, J. Brockmöller, J. Gephart, C. Meisel, J.M. Müller, R. Loddenkemper and I. Roots, Substantially reduced risk of cancer of the aerodigestive tract in subjects with variant-463A of the myeloperoxidase gene, Cancer Res 60 (2000), 644-649.

[25] N.R. Mendell and G.A. Simon, A general expression for the variance-covariance matrix of estimates of gene frequency: the effects of departures from Hardy-Weinberg equilibrium, Ann Hum Genet 48 (1984), 283-286.

[26] C.F. Cao and Q.T. Smith, Crevicular fluid myeloperoxidase at healthy, gingivitis and periodontitis sites, J Clin Periodontol 16 (1989), 17-20.

[27] D. Kaner, J.P. Bernimoulin, B.M. Kleber, W.R. Heizman and A. Friedmann, Gingival crevicular fluid levels of calprotectin and myeloperoxidase during therapy for generalized aggressive periodontitis, J Periodontol Res 41 (2006), 132-139.

[28] E. Taioli, S. Benhamou, C. Bouchardy, I. Cascorbi, N.C. Salazar, H. Dally, K.M. Fong, J.E. Larsen, L. Le Marchand, S.J. London, A. Risch, M.R. Spitz, I. Stucker, B. Weinshenker, $\mathrm{X}$. Wu and P. Yang, Myeloperoxidase G-463 A polymorphism and lung cancer: a HuGE genetic susceptibility to environmental carcinogens pooled analysis, Genet Med $\mathbf{9}$ (2007), 6773.

[29] F. Atzeni, L. Boiardi, B. Casali, E. Farnetti, P. Sarzi-Puttini, N. Pipitone, I. Olivieri, F. Cantini, F. Salvi, R. La Corte, G. Triolo, D. Filippini, G. Paolazzi and C. Salvarani, Lack of association of the $-463 \mathrm{G} / \mathrm{A}$ myeloperoxidase promoter polymorphism with Behçet's disease in Italian patients, Rheumatology 10(1093) (2007), 1-4.

[30] F.W. Asselbergs, W.F. Reynolds, J.W. Cohen-Tervaert, G.A. Jessurun and R.A. Tio, Myeloperoxidase polymorphism related to cardiovascular events in coronary artery disease, Am J Med 116 (2004), 429-430.

[31] W.F. Reynolds, M. Hiltunen, M. Pirskanen, A. Mannermaa, S. Helisalmi, M. Lehtovirta, I. Alafuzoff and H. Soininen, MPO and APOE epsilon 4 polymorphisms interact to increase risk for AD in Finnish males, Neurology 55 (2000), 1284-1290.

[32] V. Rocha, R.F. Franco, R. Porcher, H. Bittencourt, W.A. Silva Jr, A. Latouche, A. Devergie, H. Espèrou, P. Ribaud, G. Sociè, M.A. Zago and E. Gluckman, Host defense and inflammatory gene polymorphisms are associated with outcomes after HLA-identical sibling bone marrow transplantation, Blood 100 (2002), 3908-3918.

[33] S. Reichert, H.K.G. Machulla, J. Klapproth, U. Zimmermann, Y. Reichert, C.H. Gläser, H.G. Schaller, J. Stein and S. Schulz, The interleukin-10 promoter haplotype ATA is a putative risk factor for aggressive periodontitis, J Periodontol Res 43 (2008), 40-47. 


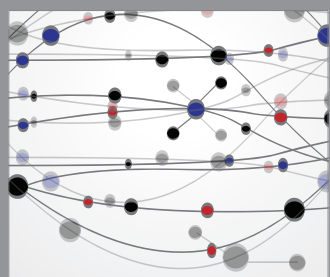

The Scientific World Journal
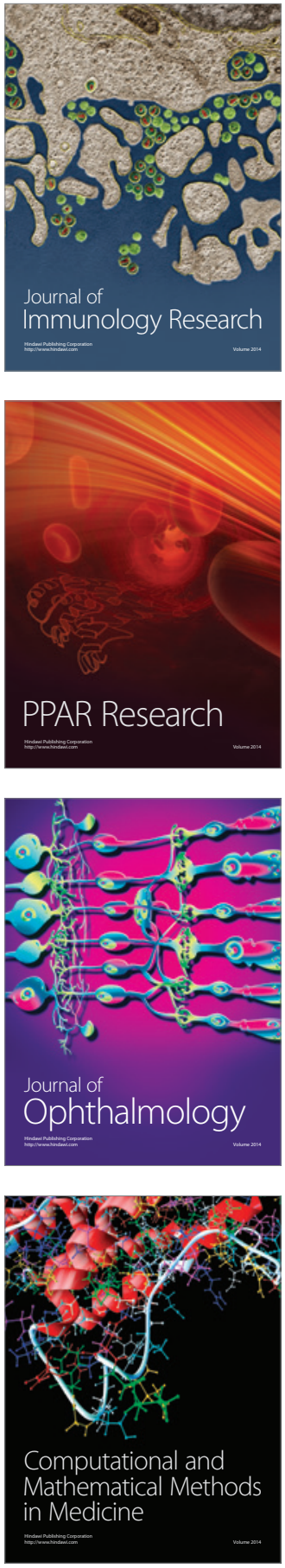

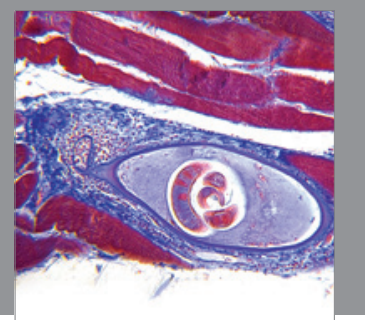

Gastroenterology

Research and Practice
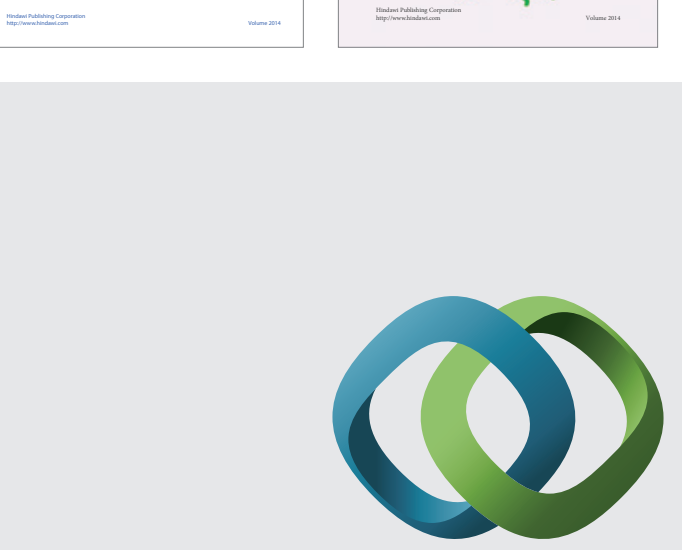

\section{Hindawi}

Submit your manuscripts at

http://www.hindawi.com
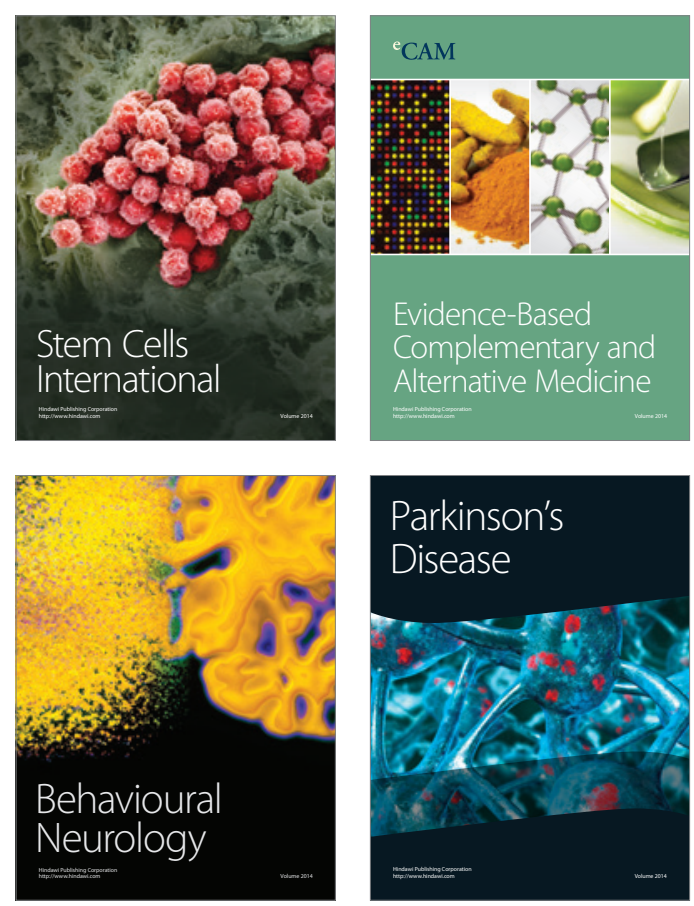

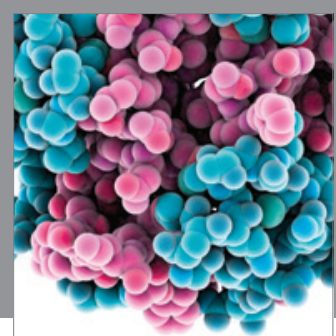

Journal of
Diabetes Research

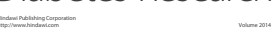

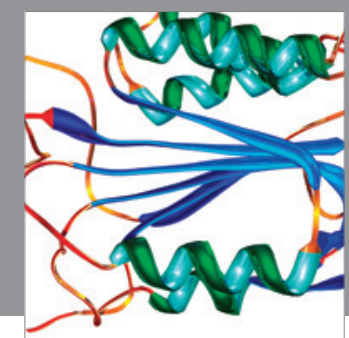

Disease Markers
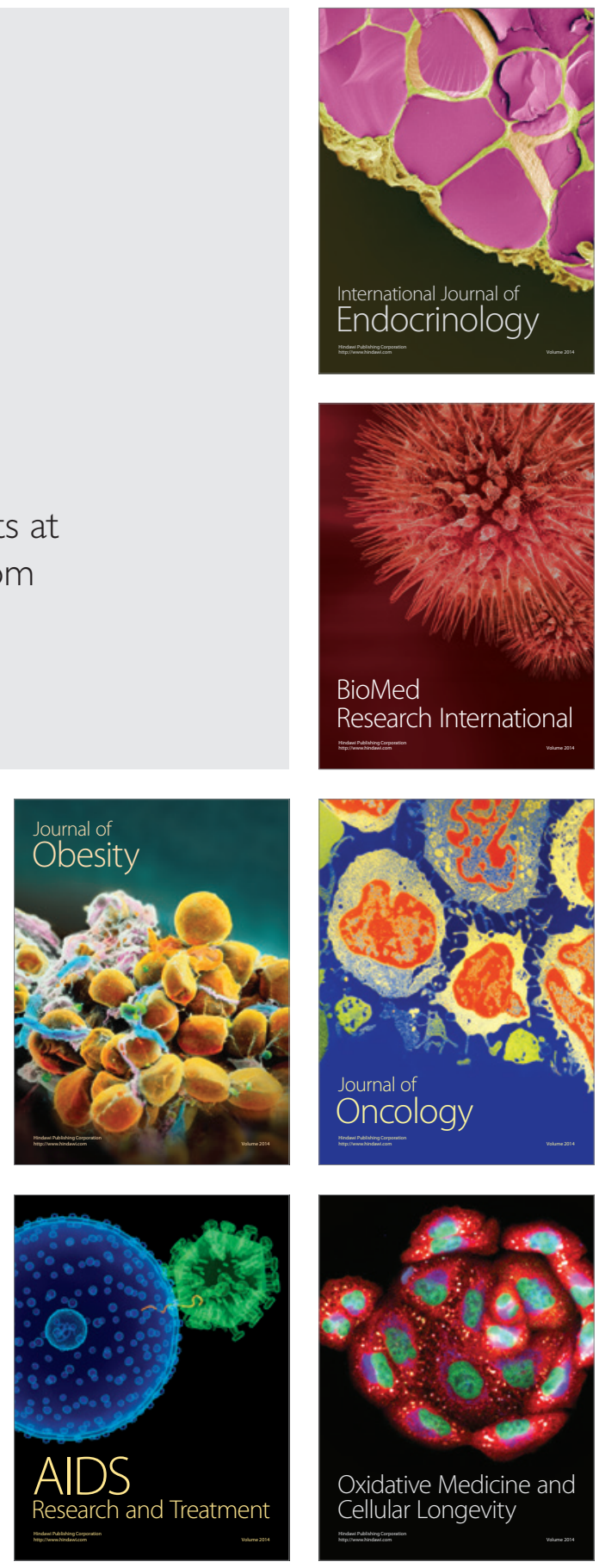